\title{
Non-surgical instrumentation associated with povidone-iodine in the treatment of interproximal furcation involvements
}

\author{
Érica Del Peloso RIBEIRO'1, Sandro BITTENCOURT ${ }^{1}$, Enilson Antônio SALLUM², Antônio Wilson SALLUM², \\ Francisco Humberto NOCITI JÚNIOR ${ }^{2}$, Márcio Zaffalon CASATI ${ }^{2}$

\begin{abstract}
1- DDS, MSc, PHD, Bahiana School of Medicine and Public Health, Salvador, BA, Brazil.
2- DDS, MSc, PHD, Department of Prosthodontics and Periodontics, Division of Periodontics, Piracicaba Dental School, University of Campinas, Piracicaba, SP, Brazil.
\end{abstract}

Corresponding address: Márcio Zaffalon Casati - Avenida Limeira, 901 - Areião - 13414-903 - Piracicaba-SP - Phone: 19-2106-5301 - Fax: 19-2106-5301 e-mail: casati@fop.unicamp.br

Received: March 11, 2009 - Modification: October 3, 2010 - Accepted: February 16, 2010

\section{ABSTRACT}

\begin{abstract}
O bjective: The aim of this controlled clinical trial was to evaluate the effect of topically applied povidone-iodine (PVP-I) used as an adjunct to non-surgical treatment of interproximal class II furcation involvements. Material and Methods: Thirty-two patients presenting at least one interproximal class II furcation involvement that bled on probing with probing pocket depth (PPD) $\geq 5 \mathrm{~mm}$ were recruited. Patients were randomly chosen to receive either subgingival instrumentation with an ultrasonic device using PVP-I $(10 \%)$ as the cooling liquid (test group) or identical treatment using distilled water as the cooling liquid (control group). The following clinical outcomes were evaluated: visible plaque index, bleeding on probing (BOP), position of the gingival margin, relative attachment level (RAL), PPD and relative horizontal attachment level (RHAL). BAPNA (N-benzoyl-Larginine-p-nitroanilide) testing was used to analyze trypsin-like activity in dental biofilm. All parameters were evaluated at baseline and 1, 3 and 6 months after non-surgical subgingival instrumentation. Results: Six months after treatment, both groups had similar means of PPD reduction, RAL and RHAL gain $(p>0.05)$. These variables were, respectively, $2.20 \pm 1.10 \mathrm{~mm}, 1.27 \pm 1.02 \mathrm{~mm}$ and $1.33 \pm 0.85 \mathrm{~mm}$ in the control group and $2.67 \pm 1.21$ $\mathrm{mm}, 1.50 \pm 1.09 \mathrm{~mm}$ and $1.56 \pm 0.93 \mathrm{~mm}$ in the test group. No difference was observed between groups at none of the posttreatment periods, regarding the number of sites showing clinical attachment gain $\geq 2 \mathrm{~mm}$. However, at 6 months posttreatment, the test group presented fewer sites with PPD $\geq 5 \mathrm{~mm}$ than the control group. Also at 6 months the test group had lower BAPNA values than control group. Conclusion: The use of PVP-I as an adjunct in the non-surgical treatment of interproximal class II furcation involvements provided limited additional clinical benefits.
\end{abstract}

Key words: Furcation defects. Dental scaling. Periodontitis. Clinical trial.

\section{INTRODUCTION}

Furcation involvements represent a great challenge to the success of periodontal therapy ${ }^{12}$. The reduced rate of success experienced in the treatment of furcation involvements seems to result from the incomplete removal of subgingival plaque and calculus in the interadicular area owing to the peculiar anatomy of the furcation space ${ }^{24,25}$. In addition, the distal location and the specific root configuration of molars limit adequate plaque control by the patient ${ }^{3}$.

Regarding the therapeutic approach, although furcation involvement treated with a conservative approach does not yield the same satisfactory results as single-rooted teeth or molar flat surfaces, it has been shown that teeth with furcation involvement have a remarkable survival rate following conservative treatment ${ }^{21}$. These findings demonstrate that the conservative approach for furcation involvement can be performed with the expectation of a high long-term survival rate for 
the patients demonstrating a satisfactory plaque control ${ }^{3}$

Del Peloso Ribeiro, et al. ${ }^{7}$ (2006) showed in a randomized controlled clinical trial that non-surgical therapy can effectively treat buccal and lingual class II furcation involvements. However, Del Peloso Ribeiro, et al. ${ }^{8}$ (2007) also showed that buccal and lingual class II furcation involvements respond better to non-surgical therapy than interproximal class II furcation involvements.

In an attempt to improve the biological response of interproximal furcation involvement to nonsurgical periodontal therapy chemotherapeutic agents could be used. Povidone-iodine (PVP-I) is one of the most potent and widely used broadspectrum antiseptics available. It has a very rapidly bactericidal effect, being effective against periodontal pathogens in vitro in as little as $15 \mathrm{~s}$ of contact and in vivo within 5 min of contact ${ }^{4,11}$. PVP-I also fails to allow the development of bacterial resistance; has low systemic toxicity and low financial $\operatorname{cost}^{2,15}$. In addition, allergic sensitization to PVP-I is rare re. $^{28}$.

PVP-I has been used as an adjunct in the treatment of chronic periodontitis with promising results $^{27}$. Rosling, et al. ${ }^{26}$ (2001) showed that PVP-I, used as the cooling liquid of an ultrasonic device, in conjunction with subgingival root debridement improved the outcome of non-surgical therapy in non-molar teeth. Hoang, et al. ${ }^{13}$ (2003) also demonstrated in non-molar teeth that the addition of subgingival PVP-I irrigation to conventional mechanical therapy caused a greater reduction in total pathogen counts.

The aim of the present study was to evaluate the effect of PVP-I, used as the cooling liquid of an ultrasonic device in the non-surgical treatment of interproximal class II furcation involvements.

\section{MATERIAL AND METHODS}

\section{Study population}

Thirty-two subjects were recruited from those referred for treatment to the Department of Periodontology of Piracicaba Dental School, State University of Campinas, Brazil. Subjects were enrolled from October 2005 to June 2006. All patients were individually informed about the nature of the proposed treatment and informed consent forms were signed. The study protocol was approved by the local Research Ethics Committee.

Power analysis indicated that 13 subjects would have $88 \%$ power to detect a $1-\mathrm{mm}$ difference in clinical attachment level between the two groups. Subjects who were invited to participate met the following inclusion criteria: 1) diagnosis of severe chronic periodontitis by the presence of periodontal pockets with clinical attachment loss $\geq 5 \mathrm{~mm}$, bleeding on probing and radiographic bone loss9; 2) at least one molar with class II interproximal furcation involvement ${ }^{10}$ that bled on probing, with probing pocket depth $\geq 5 \mathrm{~mm}$. Exclusion criteria were: 1) furcation involvement in molars with periapical disease; 2) medical disorders that could influence the response to treatment; 3) scaling and root planing in the preceding 6 months; 4) consumption of drugs known to affect periodontal status within the past 6 months; 5) pregnancy; 6) allergy to iodine; 7) thyroid dysfunction and 8) smoking habits.

\section{Study design}

This was a randomized parallel arm clinical trial with six months of duration. Patients initially received detailed information on the etiology of periodontal disease and instructions in proper self-performed plaque control measures, interdental cleaning with dental floss and interdental toothbrushes. In the initial sessions, patients also had plaque retentive factors (caries, excess of restorations and supragingival calculus) removed. The baseline measurements were performed 21 days after this initial phase.

All teeth with periodontal pocket $\geq 5 \mathrm{~mm}$ that bled on probing were treated with scaling and root planing (basic therapy). The non-surgical therapy on molars with furcation involvement was performed under local anesthesia by the use of an ultrasonic device (Profi III, Dabi Atlante, Ribeirão Preto, SP, Brazil). Specific furcation tips were used (33R and 33L; Amdent, Stockholm, Sweden). The instrumentation of furcation involvements in the test group was combined with the administration of $10 \%$ PVP-I. In this group, the traditional cooling liquid of the ultrasonic device was replaced by PVP-I for the treatment of the interproximal furcation. Thus, not all the pathological sites of the test group received PVP-I. The furcation involvements of the control group received an identical treatment, but distilled water was used as the cooling liquid. The randomization was done by coin toss right after the patient was included in the study. The allocation concealment was secured by having a person not involved in the study performing the randomization. This person was different from the one responsible for the treatment (S. B.) and different from the examiner (E. D. P. R.). The person responsible for the treatment was a specialist in periodontics. The randomization code was not broken until all data had been collected. Thus, the treatment group was not revealed to the clinical examiner or to the statistician.

Only one clinician was responsible for administering the treatment throughout the course of the study. This clinician was different from the calibrated examiner performing the clinical 
measurements. The furcation involvements were instrumented until a smooth, hard surface was achieved.

After the active treatment, all subjects were included in a maintenance program composed of professional supragingival plaque control and reinforcement of oral hygiene instructions every 15 days for the first month and every month until the sixth month. At the 3-month recall visit, sites that exhibited probing pocket depth $\geq 5 \mathrm{~mm}$ and bled on probing received subgingival therapy identical to that provided during the phase of basic therapy. The maintenance program also included an update of the medical and dental histories, extraoral and intraoral soft tissue examination, dental examination and periodontal evaluation.

\section{Clinical measurements}

The following clinical parameters were taken at baseline and at 1, 3 and 6 months after therapy. Visible plaque index (VPI) ${ }^{1}$ evaluated supragingival plaque accumulation dichotomously at six sites on all teeth in the mouth. Bleeding on probing (BOP) ${ }^{18}$ was also measured dichotomously at six sites per tooth. Thus, VPI and BOP were calculated as full mouth percentage of presence of plaque and BOP.

An individual stent was fabricated of clear selfcuring resin, with a vertical groove at the place where the furcation involvement could be probed to create fixed landmarks and to standardize the location of periodontal probes at the furcation sites. The position of the gingival margin (PGM) was measured from the stent to the gingival margin and the relative attachment level ( $R A L$ ) from the stent to the bottom of the periodontal pocket. The probing pocket depth (PPD) was calculated based on RAL and PMG. The relative horizontal attachment level (RHAL) was measured, using a curved periodontal probe (Neumar, São Paulo, SP, Brazil) with grooves at $1 \mathrm{~mm}$ intervals ${ }^{29}$ from the stent to the deepest horizontal point of the periodontal pocket. The clinical parameters VPI, BOP, PGM, RAL and PPD were measured using a standardized periodontal probe with $1 \mathrm{~mm}$ markings (PCPUNC 15 ${ }^{\circledR}$; $\mathrm{Hu}-$ Friedy, Chicago, IL, USA).

\section{Examiner Calibration}

The investigator charged with clinical assessments was calibrated for intraexaminer repeatability prior to the start of the trial. Three patients with chronic periodontitis were enrolled for this purpose. Duplicate measurements $(\mathrm{N}=414)$ for PPD, RAL and RHAL were collected with an interval of $24 \mathrm{~h}$ between the first and the second recording. The intraclass correlation coefficients as a measure of intraexaminer reproducibility were $0.81,0.88$ and 0.89 for mean PPD, RAL and RHAL, respectively.
Biochemical evaluation - BAPNA assay

The biochemical evaluation was done with the BAPNA test that permits the detection of microorganisms possessing trypsin-like enzymes such as Tannerella forsythensis, Treponema denticola and Porphyromonas gingivalis. Subgingival dental plaque was collected from furcation involvements with sterile Gracey curettes. Before the collection, the area was dried, isolated and had the supragingival plaque removed.

The plaque collected was placed in preweighed coded microcentrifuge tubes. To the tubes was added $1 \mathrm{~mL}$ of a solution containing the enzyme substrate $\mathrm{N}$-benzoyl-L-arginine-p-nitroanilide (BAPNA; Sigma, St. Louis, MO, USA) with a final concentration of $1.0 \mathrm{nmol} / \mathrm{L}$ in the assay buffer (0.05 nmol/L Tris- $\mathrm{HCl}, 5 \mathrm{mM} \mathrm{CaCl}, \mathrm{pH} 7.5)$ that had $5 \%$ DMSO. This suspension was vortexed and then placed in an ultrasound bath on ice for $10 \mathrm{~min}$ with 2-s cycles and 2-s intervals at $17 \mathrm{~W}$ using a $100 \mathrm{~W}$ ultrasonic processor. After $17 \mathrm{~h}$ of incubation at $37^{\circ} \mathrm{C}$, the reaction was stopped with ice and by the addition of $100 \mu \mathrm{L}$ of glacial acetic acid. The absorbance was read at $405 \mathrm{~nm}$. The results were given in nanomoles of product per minute per milligram of dental plaque wet weight ${ }^{20}$.

\section{Statistical analysis}

Repeated measures analysis of variance (ANOVA) was used to detect intra and intergroup differences in clinical parameters (VPI, BOP, PPD, RAL and RHAL). When statistical significance was found, analysis of the difference was determined using the method of Tukey. The proportion of sites presenting PPD $\geq 5 \mathrm{~mm}$, RAL gain $\geq 2 \mathrm{~mm}$, plaque and bleeding on probing at the furcation sites and number of lesions retreated at 3 and 6 months were compared between groups with chi-square analysis or Fischer's exact test. The Friedman test was used to detect intragroup differences in biochemical parameter among all periods and the Mann-Whitney test to detect intergroup differences in this parameter at each time interval. All evaluations used the subject as the unit of measurement; averages were used if more than one site per subject existed. Individual furcation involvements were compared regarding the RAL gain $\geq 2 \mathrm{~mm}$, the occurrence of BOP, and the number of sites referred for treatment and PPD $\geq 5 \mathrm{~mm}$. All analysis was done with SAS Software 2001-Release 8.2 (SAS Institute Inc., Cary, North Carolina, USA). An experimental level of significance (alpha) was set at 0.05. RAL was considered as the primary outcome variable. All other parameters were considered secondary outcomes. 


\section{RESULTS}

Four patients did not show up for all the appointments, for reasons not related to the study; and thus, a total of 28 patients completed the study: 15 of the control group and 13 of the test group. A total of 37 furcation involvements were evaluated: 18 in the control group and 19 in the test group. The baseline data indicated that control and test groups were similar according to age, gender, clinical and biochemical parameters (Table 1 ).
Visible plaque index (VPI) and bleeding on probing (BOP)

VPI and BOP were reduced during the study in both groups, but no statistically significant difference was found between them (Table 2). BOP were measured for the whole mouth and also exclusively at the furcation involvements. In this case, no difference was observed between groups (Figure 1).

Table 1- Baseline means ( \pm standard deviation) of age, gender, clinical and biochemical parameters*

\begin{tabular}{lcc}
\hline CARACTERISTIC & CONTROL GROUP & TEST GROUP \\
\hline Age (range/ mean) & $26-57 / 42.96$ years & $27-59 / 43.74$ years \\
$\%$ Males & $47.37 \%$ & $46.15 \%$ \\
VPI $(\%) \dagger$ & $45.30( \pm 13.08)$ & $43.96( \pm 16.02)$ \\
BOP $(\%)$ & $34.60( \pm 11.05)$ & $31.83( \pm 13.91)$ \\
PGM $(\mathrm{mm})$ & $2.35( \pm 0.68)$ & $2.31( \pm 1.03)$ \\
PPD $(\mathrm{mm})$ & $6.98( \pm 1.53)$ & $7.00( \pm 1.00)$ \\
RAL $(\mathrm{mm})$ & $9.33( \pm 1.64)$ & $9.31( \pm 1.07)$ \\
RHAL $(\mathrm{mm})$ & $10.22( \pm 3.07)$ & $10.97( \pm 1.72)$ \\
BAPNA $(\mathrm{nmol} / \mathrm{mg} \times \mathrm{min})$ & $37.45( \pm 26.18)$ & $45.97( \pm 22.22)$ \\
\hline
\end{tabular}

* At baseline, no significant differences were noted in demographic, clinical or biochemical parameters between groups (analysis by non-paired t test for age, by repeated measures ANOVA for clinical parameters and by Mann-Whitney test for biochemical parameter)

† Note: Values of VPI and BOP refer to means of the whole mouth while values of PPD, CAL, RHAL and BAPNA refer to means of the furcation sites

$\mathrm{VPI}=$ visible plaque index; $\mathrm{BOP}=$ bleeding on probing; $\mathrm{PGM}=$ position of the gengival margin; $\mathrm{PPD}=$ probing pocket depth; $\mathrm{RAL}=$ relative attachment margin; $\mathrm{RHAL}=$ relative horizontal attachment level; BAPNA= N-benzoyl-L-arginine-p-nitroanilide

Table 2- Mean \pm SD of visible plaque index (VPI) and bleeding on probing (BOP) values (\%) at different time intervals for control and test groups*

\begin{tabular}{lcc}
\hline TIME INTERVAL & CONTROL GROUP & TEST GROUP \\
\hline VPI & & \\
baseline & $45.29 \pm 13.08$ & $43.95 \pm 16.02$ \\
1 month & $39.74 \pm 16.39$ & $46.21 \pm 13.19$ \\
3 months & $35.24 \pm 13.98^{* *}$ & $32.52 \pm 10.34^{* *}$ \\
6 months & $34.57 \pm 12.09^{* *}$ & $30.51 \pm 13.96^{* *}$ \\
BOP & $34.60 \pm 11.04$ & $31.83 \pm 13.91$ \\
baseline & $25.01 \pm 9.44^{* * *}$ & $21.03 \pm 11.08^{* * *}$ \\
1 month & $21.47 \pm 10.13^{* * *}$ & $19.23 \pm 8.47^{* * *}$ \\
3 months & $19.98 \pm 6.07^{* * *}$ & $18.37 \pm 8.07^{* * *}$ \\
\hline 6 months & & \\
\hline
\end{tabular}

* No significant differences were noted in VPI and BOP, of all teeth, between groups (analysis by repeated measures ANOVA)

** Significant reduction $(p<0.05)$ from baseline and 1 month values (analysis by repeated measures ANOVA and Tukey test)

*** Significant reduction $(p<0.05)$ from baseline (analysis by repeated measures ANOVA and Tukey test) 


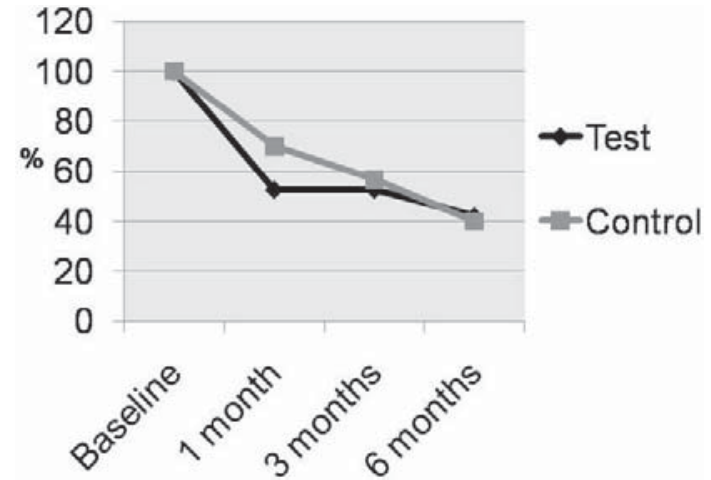

Figure 1- Bleeding on probing (BOP) of furcation involvements at different time intervals for control and test groups

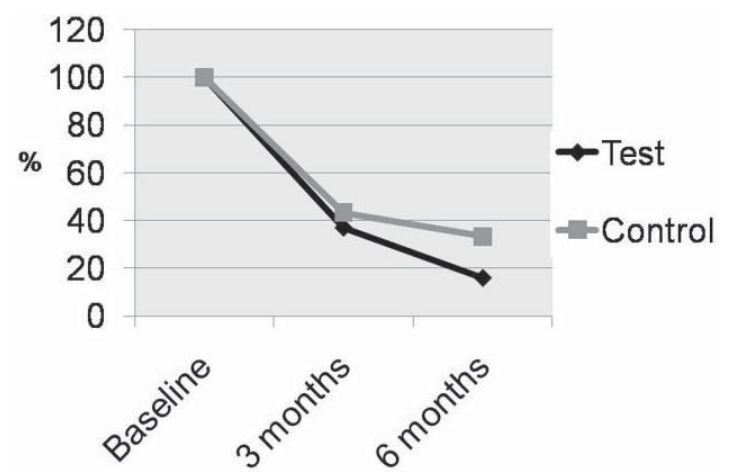

Figure 3- Percentage of furcation involvements that needed re-treatment at different time intervals for control and test groups

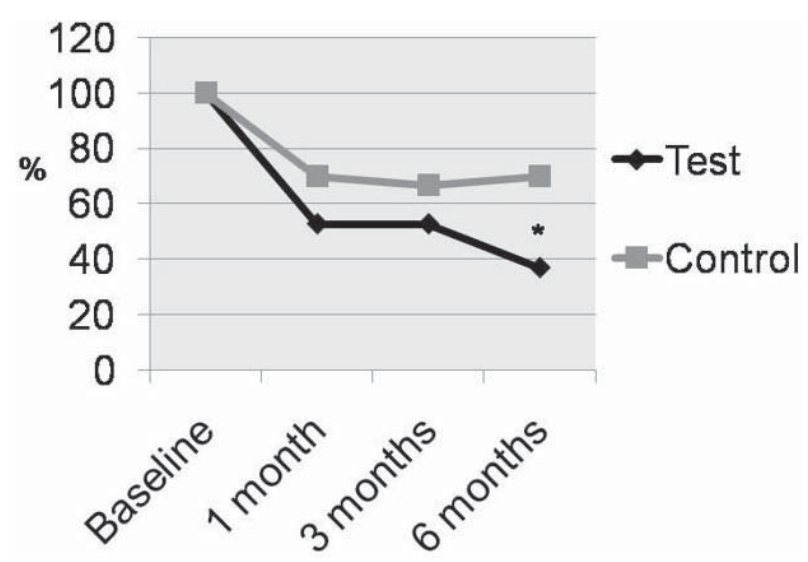

Figure 2- Percentage of furcation involvements with probing pocket depth (PPD) $\geq 5 \mathrm{~mm}$ atdifferent time intervals for control and test groups.

* Difference $(p<0.05)$ between groups by chi-square test.

\section{Clinical parameters - PGM, PPD, RAL and RHAL \\ Both groups showed, without significant} difference between them, an increase in PGM, a reduction in PPD and a gain in RAL and RHAL (Table 3 ). At 6 months, the mean decrease in PPD was $2.20 \pm 1.10 \mathrm{~mm}$ in control group and $2.67 \pm 1.21 \mathrm{~mm}$ in test group. The mean gain in RAL and RHAL was $1.27 \pm 1.02 \mathrm{~mm}$ and $1.33 \pm 0.85 \mathrm{~mm}$ in the control group and $1.50 \pm 1.09 \mathrm{~mm}$ and $1.56 \pm 0.93 \mathrm{~mm}$ in the test group, respectively. The results of PMG, PPD, RAL and RHAL refer strictly to the furcation sites.

Table 3- Mean \pm standard deviation of position of the gengival margin (PGM), probing pocket depth (PPD), relative attachment margin (RAL) and relative horizontal attachment level (RHAL) $(\mathrm{mm})$ at different time intervals for control and test groups

\begin{tabular}{lcc}
\hline TIME INTERVAL & CONTROL GROUP & TEST GROUP \\
\hline PGM & & \\
Baseline & $2.40 \pm 1.06$ & $2.00 \pm 0.97$ \\
1 month & $3.00 \pm 1.11^{*}$ & $2.89 \pm 1.13^{*}$ \\
3 months & $3.13 \pm 0.94^{*}$ & $3.22 \pm 1.00^{*}$ \\
6 months & $3.33 \pm 0.99^{*}$ & $3.17 \pm 1.20^{*}$ \\
PPD & & \\
Baseline & $7.10 \pm 1.71$ & $7.11 \pm 1.67$ \\
1 month & $5.13 \pm 1.2^{*}$ & $5.05 \pm 1.16^{*}$ \\
3 months & $5.00 \pm 1.26^{*}$ & $4.83 \pm 1.29^{*}$ \\
6 months & $4.90 \pm 0.96^{*}$ & $4.44 \pm 1.19^{*}$ \\
RAL & & \\
Baseline & $9.50 \pm 2.05$ & $9.11 \pm 1.81$ \\
1 month & $8.13 \pm 1.57^{*}$ & $7.94 \pm 1.62^{*}$ \\
3 months & $8.13 \pm 1.63^{*}$ & $8.05 \pm 1.39^{*}$ \\
6 months & $8.23 \pm 1.30^{*}$ & $7.61 \pm 1.46^{*}$ \\
\hline RHAL & & \\
\hline Baseline & $11.20 \pm 2.34$ & $10.61 \pm 2.20$ \\
1 month & $10.00 \pm 1.89^{*}$ & $10.17 \pm 2.55^{*}$ \\
3 months & $9.73 \pm 1.64^{*}$ & $9.72 \pm 2.05^{*}$ \\
6 months & $8.87 \pm 1.65^{*}$ & $9.05 \pm 1.70^{*}$ \\
\hline
\end{tabular}

* Significant difference from baseline value (analysis by ANOVA and Tukey test) 
Table 4- N-benzoyl-L-arginine-p-nitroanilide (BAPNA) results (nmol product/mg dental biofilm/minute) at different time intervals for control and test groups

\begin{tabular}{lcc}
\hline TIME INTERVAL & \multicolumn{2}{c}{ BAPNA } \\
\hline & CONTROL GROUP & TEST GROUP \\
\hline Baseline & $37.45 \pm 26.18$ & $45.97 \pm 22.22$ \\
1 month & $21.58 \pm 24.87^{*}$ & $17.95 \pm 8.76^{*}$ \\
3 months & $17.59 \pm 15.71^{*}$ & $23.38 \pm 20.88^{*}$ \\
6 months & $39.98 \pm 38.14 \dagger$ & $18.10 \pm 14.61^{*} \dagger$ \\
\hline
\end{tabular}

* Significant difference from baseline value (analysis by Friedman test)

† Significant difference between groups (analysis by Mann-Whitney test)

There was no difference between groups regarding the proportions of furcation presenting RAL gain $\geq 2 \mathrm{~mm}$. At the first month after treatment, the control group had $36.67 \%$ of sites showing a RAL gain $\geq 2 \mathrm{~mm}$ and the test group had $42.10 \%$. At 3 months, these values were $30.00 \%$ and $26.31 \%$ and at 6 months, $33.33 \%$ and $42.10 \%$, respectively.

Difference between groups was found regarding the proportion of sites with PPD $\geq 5 \mathrm{~mm}$ at 6 months after treatment (Figure 2). All furcations presented PPD $\geq 5 \mathrm{~mm}$ at baseline. At the first month after therapy, $70.00 \%$ of the furcation involvements still had PPD $\geq 5 \mathrm{~mm}$ in the control group and $52.63 \%$ had this PPD in the test group. At 3 months, the values were $66.67 \%$ and $52.63 \%$, respectively. At 6 months, $70.00 \%$ of the evaluated sites had PPD $\geq 5 \mathrm{~mm}$ in the control group and $36.84 \%$ in the test group $(p=0.04)$.

The percentage of furcation sites that needed retreatment at 3 months was $43.33 \%$ in the control group and $36.84 \%$ in the test group. At 6 months, the values were $33.33 \%$ and $15.79 \%$, respectively. These differences were not statistically different (Figure 3).

\section{Biochemical parameter - BAPNA test}

Table 4 presents the results of BAPNA at different time intervals. Both groups, at one and three months after treatment, showed a statistically significant reduction of the trypsin-like enzyme activity in subgingival biofilm, without difference between groups. At 6 months, only the test group presented BAPNA value significantly different from baseline. There was also a significant difference between groups on BAPNA values at 6 months.

\section{DISCUSSION}

The conservative approach of furcation involvements is effective in the treatment of buccal and lingual class II furcation lesions in patients demonstrating a satisfactory plaque control ${ }^{7}$. However, interproximal furcation involvements do not show the same biological response to non-surgical treatment probably because of the irregular anatomy of the area that impairs professional plaque control procedures and because of the difficulties faced by the patient to maintain plaque control ${ }^{3,8}$. In an attempt to overcome these difficulties antimicrobials agents could be used. Because PVP-I is a potent antiseptic and its use in the treatment of non-molar teeth with chronic periodontitis has shown promising results ${ }^{13,26}$, the present study has been designed to evaluate the use of locally applied PVP-I as an adjunct to nonsurgical therapy of interproximal class II furcation involvements.

However, in the present study, both groups presented similar means of PPD reduction and RAL and HRAL gain. No benefit on the use of antimicrobials in the treatment of class II mandibular furcation was also shown by Tonetti, et al. ${ }^{30}$ (1998).

In the present study, difference between groups was observed, at 6 months, in BAPNA values. Test group had lower levels of trypsin-like activity than the control group. Trypsin-like enzyme is produced by important periodontal pathogens such as Tannerella forsythia, Treponema denticola and Porphyromonas gingivalis and is associated with signs of periodontitis ${ }^{32}$. These microorganisms are increased in diseased sites, when compared to stable ones ${ }^{22}$. Strong evidence also supports the report of $T$. forsythia and $P$. gingivalis as risk indicators of periodontal disease ${ }^{33}$. This information raises the doubt if the lower values of BAPNA in the group where PVP-I was used will be followed by a lower average of disease recurrence.

The BAPNA results could be related to the higher percentage of sites presenting, at 6 months, PPD $\geq 5 \mathrm{~mm}$ in the control group than in the test group. This is an important result since according to Claffey and Egelberg ${ }^{6}$ (1995) patients demonstrating a high proportion of deep pockets following initial cause related therapy are more likely to experience further clinical attachment loss.

However, no difference was observed in the number of sites referred for re-treatment. This 
parameter is an important indicator of the clinical significance of treatment because it relates to the percentage of sites that returned to health and to the percentage of sites still requiring therapy ${ }^{14}$. Sites with PPD $\geq 5 \mathrm{~mm}$ and BOP were re-treated. BOP is an important outcome measurement as the absence of bleeding on probing in recall patients has been associated with clinical stability over time ${ }^{16}$. BOP and PPD are the accepted indicators of the response to root debridement ${ }^{31}$. At 3 and 6 months after therapy the percentage of sites re-treated was $30.00 \%$ and $33.33 \%$ in the control group and $26.31 \%$ and $42.10 \%$ in the test group, respectively. This means that at 6 months only $66.67 \%$ of control group and $58.90 \%$ of test group had PPD $\leq 5 \mathrm{~mm}$ without BOP.

Interproximal furcation involvements are difficult to treat not only with non-surgical therapy, but also with guided tissue regeneration. In a regeneration furcation study, the largest clinical improvement was found in class II furcation defects of mandibular molars, followed by buccal class II furcations of maxillary molars and, interproximal furcation lesions exhibiting the least or no improvement ${ }^{23}$.

The difficulties in the treatment of interproximal furcation involvement could not be overcome by the use of PVP-I as adjunct to non-surgical therapy even with the use of ultrasonic tips specifically design to access the furcation area. These tips were used since it is known that areas inaccessible to instruments are also inaccessible to the cooling liquid. Also it has been shown that furcation entrances have in general smaller dimensions than the width of a Gracey curette, but they are larger than the average dimension of a new standard ultrasonic tip ${ }^{5}$. This is in accordance with the finding that ultrasonic instruments are more effective than hand scaling in reducing gingival fluid flow and bacterial proportions of spirochetes and other motile organisms in class II and III furcation involvements ${ }^{17}$.

The decision to employ a $10 \%$ solution of PVP-I was based on findings by Nakagawa, et al. ${ }^{19}$ (1990). They determined that only the in vivo undiluted PVP-I solution significantly reduced the total colony forming units of subgingival pockets. Other in vitro studies showed bactericidal effect with lower concentration of PVP-I ${ }^{27}$. However, in vitro data may not reflect in vivo results because intraoral findings can be affected by salivary dilution, protein deactivation, and the inability of drugs to penetrate bacterial biofilms. Hoang, et al. ${ }^{13}$ (2003) also used 10\% PVP-I subgingival irrigation in periodontitis lesions showing radiographic evidence of subgingival calculus.

\section{CONCLUSION}

It may be concluded, based on the design of the study, that the use of PVP-I, as the cooling liquid of an ultrasonic device in the non-surgical treatment of interproximal class II furcation involvements provided limited additional clinical benefits.

\section{ACKNOWLEDGEMENTS}

The authors thank Drs. Gláucia Maria Bovi Ambrosano for the assistance in the statistical analysis.

\section{REFERENCES}

1- Ainamo J, Bay I. Problems and proposals for recording gingivitis and plaque. Int Dent J. 1975;25:229-35.

2- Burks RI. Povidone-iodine solution in wound treatment. Phys Ther. $1998 ; 78: 212-8$.

3- Cattabriga M, Pedrazzoli V, Wilson TG Jr. The conservative approach in the treatment of furcation lesions. Periodontol 2000. 2000;22:133-53.

4- Caufield PW, Allen DN, Childers NK. In vitro susceptibilities of suspected periodontopathic anaerobes as determined by membrane transfer assay. Antimicrob Agents Chemother. 1987;31:1989-93.

5- Chiu BM, Zee KY, Corbet EF, Holmgren CJ. Periodontal implications of furcation entrance dimensions in Chinese first permanent molars. J Periodontol. 1991;62:308-11.

6- Claffey N, Egelberg J. Clinical indicators of probing attachment loss following initial periodontal treatment in advanced periodontites patients. J Clin Periodontol. 1995;22:690-6.

7- Del Peloso Ribeiro E, Bittencourt S, Ambrosano GM, et al. Povidone-iodine used as an adjunct to non-surgical treatment of furcation involvements. J Periodontol. 2006;77:211-7.

8- Del Peloso Ribeiro E, Bittencourt S, Nociti FH Jr, Sallum EA, Sallum AW, Casati MZ. Comparative study of ultrasonic instrumentation for the non-surgical treatment of interproximal and non-interproximal furcation involvements. J Periodontol. 2007;78:224-30.

9- Flemmig TF. Periodontitis. Ann Periodontology. 1999;4:32-8. 10- Hamp SE, Nyman S, Lindhe J. Periodontal treatment of multi-rooted teeth. Results after 5 years. J Clin Periodontol. $1975 ; 2: 126-35$.

11- Higashitsutsumi M, Kamoi K, Miyata H, Ohgi S, Shimizu $T$, Koide $K$, et al. Bactericidal effects of povidone-iodine solution to oral pathogenic bacteria in vitro. Postgrad Med J. 1993;69(Suppl.3):S10-4.

12- Hirschfeld L, Wasserman B. A long-term survey of tooth loss in 600 treated periodontal patients. J Periodontol. 1978;49:225-37. 13- Hoang T, Jorgensen MG, Keim RG, Pattison AM, Slots J. Povidone-iodine as a periodontal pocket disinfectant. J Periodont Res. 2003;38:311-7.

14- Killoy WJ. The clinical significance of local chemotherapies. J Clin Periodontol. 2002;29(Suppl. 2):22-9.

15- Kunisada T, Yamada K, Oda S, Hara O. Investigation on the efficacy of povidone-iodine against antiseptic-resistant species. Dermatology. 1997;195(Suppl. 2):14-8.

16- Lang NP, Adler R, Joss A, Nyman S. Absence of bleeding on probing. An indicator of periodontal stability. J Clin Periodontol. 1990;17:714-21.

17- Leon LE, Vogel RI. A comparison of the effectiveness of hand scaling and ultrasonic debridement in furcations as evaluated by differential dark-field microscopy. J Periodontol. 1987;58:86-94. 18- Mühlemann HR, Son S. Gingival sulcus bleeding - a leading symptom in initial gingivitis. Helv Odontol Acta. 1971;15:107-13. 19- Nakagawa T, Saito A, Hosaka Y, Yamada S, Tsunoda M, Sato $\mathrm{T}$, et al. Bactericidal effects on subgingival bacteria of irrigation with a povidone-iodine solution (Neojodin). Bull Tokyo Dent Coll. 1990;31(3):199-203. 
20- Nogueira-Filho GR, Duarte PM, Toledo S, Tabchoury CPM, Cury JA. Effect of triclosan dentifrices on mouth volatile sulphur compounds and dental plaque trypsin-like activity during experimental gingivitis development. J Clin Periodontol. 2002;29:1059-64.

21- Nordland P, Garrett S, Kiger R, Vanooteghem R, Hutchens LH, Egelberg $\mathrm{J}$. The effect of plaque control and root debridement in molar teeth. J Clin Periodontol. 1987;14:231-6.

22- Papapanou PN, Baelum V, Luan WM, Madianos PN, Chen $\mathrm{X}$, Fejerskov $\mathrm{O}$, et al. Subgingival microbiota in adult Chinese: prevalence and relation to periodontal disease progression. J Periodontol. 1997;68:651-66.

23- Pontoriero R, Lindhe J. Guided tissue regeneration in the treatment of degree II furcations in maxillary molars. J Clin Periodontol. 1995;22:756-63.

24- Porciúncula HF, Porciúncula MM, Zuza EP, Toledo BE. Biometric analysis of the maxillary permanent molar teeth and its relation to furcation involvement. Braz Oral Res. 2004;18:187-91.

25- Rios CM, Pustiglioni FE, Romito GA. Biometric study of the width, length and depth of the root trunk groove of human lower second molars. Pesqui Odontol Bras. 2002;16:26-30.

26- Rosling B, Hellström MK, Ramberg P, Socransky SS, Lindhe J. The use of PVP-iodine as an adjunct to non-surgical treatment of chronic periodontitis. J Clin Periodontol. 2001;28:1023-31.

27- Rosling BG, Slots J. Christersson LA, Gröndahl HG, Genco RJ. Topical antimicrobial therapy and diagnosis of subgingival bacteria in the management of inflammatory periodontal disease. J Clin Periodontol. 1986;13:975-81.
28- Schreier H, Erdos G, Reimer K, König B, König W, Fleischer W. Molecular effects of povidone-iodine on relevant microorganisms: an electron-microscopic and biochemical study. Dermatology. 1997;195(Suppl. 2):111-6.

29- Suh YI, Lundgren T, Sigurdsson T, Riggs M, Crigger M. Probing bone level measurements for determination of the depths of Class II furcation defects. J Periodontol. 2002;73:637-42.

30- Tonetti MS, Cortellini P, Carnevale G, Cattabriga M, de Sanctis M, Pini Prato GP. A controlled multicenter study of adjunctive use of tetracycline periodontal fibers in mandibular class II furcations with persistent bleeding. J Clin Periodontol. 1998;25:728-36.

31- Vanooteghem R, Hutchens LH, Garrett S, Kiger R, Egelberg J. Bleeding on probing and probing depth as indicators of the response to plaque control and root debridement. J Clin Periodontol. 1987;14:226-30.

32- Wetzel AC, Neuenschwander-Schüpbach A, Lopatin DE, Lang NP. Use of BANA hydrolysis as a diagnostic test for identifying periodontopathic environments. Schweiz Monatsschr Zahnmed. $1991 ; 101: 1127-32$.

33- Yano-Higuchi K, Takamatsu N, He T, Umeda M, Ishikawa I. Prevalence of Bacteroides forsythus, Porphyromonas gingivalis and Actinobacillus actinomycetemcomitans in subgingival microflora of Japanese patients with adult and rapidly progressive periodontitis. J Clin Periodontol. 2000;27:597-602. 